\title{
Implementation of Telematics Solutions in Urban Agglomerations in the Aspect of Road Incidents
}

\author{
Ibrahiem M. M. El Emary ${ }^{1}$, Anna Brzozowska² \& Bubel Dagmara ${ }^{3}$ \\ ${ }^{1}$ King Abdulaziz University, Jeddah, Saudi Arabia \\ ${ }^{2}$ Departament of Business Informatics, Częstochowa University of Technology, Poland \\ ${ }^{3}$ Main Library, Czestochowa University of Technology, Poland \\ Correspondence: Ibrahiem M. M. El Emary, Professor of computer science and systems, King Abdulaziz University, \\ Jeddah, Saudi Arabia. E-mail: omary57@hotmail.com
}

Received: October 30, 2019

Accepted: November 15, 2019

Online Published: December 22, 2019

doi:10.5430/rwe.v10n4p1

URL: https://doi.org/10.5430/rwe.v10n4p1

\begin{abstract}
Urban mobility is a public service provided by a road traffic management entity. The customer receives access to the road infrastructure and a service of travelling in a city by a transport means of their choice. In the case of road traffic incident management, this issue is becoming increasingly important, as every traffic management entity should deliver a product that meets road users' requirements and expectations. A characteristic element of road traffic management is incidents generated by road infrastructure users that occur at each stage of traffic management. The paper presents the results of research carried out in the aspect of use of appropriate algorithms of traffic incident management on selected national roads, supported by research and scientific discourse on aspects related to telematics systems, with particular emphasis on Intelligent Transport Systems, in order to verify the effectiveness of the implementation of telematics solutions. The issues mentioned above are extremely important in view of the need to acknowledge the expected critical infrastructure. Principles and recommendations used in the selection and implementation of ITS applications become an important element in this respect. The research was used to verify the effectiveness of event management algorithms in road traffic, with different traffic volume and meteorological conditions. Empirical findings used in research allow for the analysis of changes in traffic parameters, such as vehicle speed, traffic volume and detector occupancy, on selected national roads, at specific intervals. This has made it possible to determine the prospects for the development of traffic incident management algorithms, which constitute a set of artificial intelligence methods.
\end{abstract}

Keywords: algorithms, road infrastructure traffic incident management, IST, ISL

\section{Introduction}

According to the assumptions of the concept of Smart City, the best results can be achieved through integration of knowledge from different areas of the economy by means of modern technologies (Schieweck, S., Kern-Isberner, G., \& Ten Hompel, M., 2018). The idea behind Intelligent Transportation Systems is synergy of advanced technological solutions from different areas of the economy designed to improve the current functioning of transportation systems, thus increasing their effectiveness and reducing their negative environmental impact (Schonlau, B., Krumbiegel, K., \& Seidel, D., 2018). Intelligent Transportation Systems constitute a link between modern technology and solutions for communication and operation of advanced IT tools. Combining these two components gave rise to a new concept - telematics - i.e. method that consists in using telecommunication, information and IT tools to automate tasks connected with operation of transportation systems. Transportation telematics consists of physical systems that have been improved by means of telematic tools and modern management methods. Internet applications that enable data exchange between a system and its users are also used. The structure of Intelligent Transportation Systems comprises solutions from such area as IT and communication which, supported by telematics and modern management methods, enable an effective and efficient control and management of vehicle traffic. Communication between the system and its users is possible through Internet applications, which enable inhabitants with Internet access to view different elements of Intelligent Transportation Systems from any place. The topicality of the indicated subject matter is dictated by the need to create a knowledge base on algorithms of traffic event management occurring within the road 
infrastructure, taking into account the speed of vehicles, traffic volume and occupancy of detectors in a specified period of time.

\section{Analysis of Literature and Problem Statement}

Literature reviews have shown the existence of many assumptions concerning traffic incident management in the aspect of road infrastructure. The choice of the right assumption depends on individual needs. This creates an opportunity to create a specific road traffic event management system and at the same time poses a challenge to infrastructure conditions. When choosing the right traffic incident management algorithms, compatibility and the ability to combine them is of paramount importance. Due to the constantly growing interest in intelligent logistic systems, shown in recent years, the authors predict a permanent increase in the dissemination and application of, first of all, the possibility of using algorithms presented in this article to forecast the management of traffic incidents in the aspect of road infrastructure.

Traffic events can be managed with the use of appropriate algorithms for Intelligent Transport Systems (ITS) equipment and applications. Random traffic incidents reduce the throughput of the traffic system components and increase time loss and the likelihood of secondary events, which are often dangerous traffic incidents. Sven Fröhlich and others have classified road incidents (Fröhlich, S., et al., 2018). Detection and verification of an incident is the first stage of the traffic incident management process, followed by the start of rescue action and traffic management in response to the incident, removal of the consequences of the incident and restoring normal traffic conditions. Manfred Harrer and others indicated the benefits of reducing serial and secondary events (up to 29\%), reducing drivers' working time, reducing fuel consumption and emissions (Harrer, Manfred, et al., 2018). On the other hand, Jörg Dreier's research showed that traffic incident management, in terms of road infrastructure, contributed to reducing the time from incident reporting to rescue at the scene of the accident by 50\%, and from incident reporting to cleaning up the scene of the accident by $38 \%$ (Dreier, J., 2018). According to Michael Schäfer and Robert Hoyer, the implementation of traffic incident management algorithms allowed the duration of the traffic incident to be shortened by 30 minutes on average.

The first objective of implementing traffic incident management algorithms is to enable the capacity of the existing traffic systems to be used more efficiently in the event of an incident. This objective is being achieved by influencing the traffic distribution and reducing the probability of a traffic event (Schäfer, M., \& Hoyer, R., 2017). It is also important to be able to collect data from the detection system, which serves basis for improving the traffic incident management strategy, as confirmed by Stephan Pieper, Felix Kunde and Petra Sauer (Pieper, S., Kunde, F., \& Sauer, P., 2018). Thomas Kleine-Besten and others also discussed the methods of detecting traffic events, emphasizing the use of algorithms that allow for the analysis of changes in traffic parameters such as vehicle speed, traffic volume, occupancy of detectors or the time of covering a section of the road (Kleine-Besten, T., et al., 2015). Achim Reusswig, on the basis of the ongoing divagations, emphasized the fact, that in most algorithms one decision is made - about the occurrence of an event in traffic or its absence in a given time interval in relation to the detection station. In his opinion, ways of determining the detection rate are different, due to different ways of calculation. If the algorithm has been analysing the data for a longer period of time, the results are likely to be more satisfactory. The aim of the algorithm is to minimize the time needed for a detection of a traffic incident, hence a balance between the performance parameters of the method used should be maintained, with an acceptable number of false alarms, an acceptable time of detection and a satisfactory detection rate should be maintained (Reusswig, A., 2018). The so far developed traffic incident management algorithms have been divided into four main groups: algorithms based on reference models, disaster theory, statistical calculations and artificial intelligence (Hochgürtel, H., 2018).

\section{The Purpose and Objectives of the Study}

The aim of the work is to identify the issues concentrated around traffic event management systems, using Intelligent Transport Systems and algorithms in the aspect of road infrastructure. To that end, implementation variants, functions and effects of the implementation of intelligent transport systems on selected national roads were presented. The effectiveness of the implementation of appropriate algorithms has also been verified, taking into account the current literature.

The main aim of the article is to analyze the event management system in the aspect of road infrastructure, including the critical one, which is based on Intelligent Transport Systems, using ICT modules, in order to prepare forecasts for making decisions that are of key importance for safety. This ensures effective implementation and combination of appropriate algorithms and artificial intelligence teams. Implementation of the assumptions related to road management in the sense of improving the effectiveness of the algorithms being researched, allows the use of IST and ISL applications, creating the possibility of more effective use of road infrastructure in the event of an incident. 
Since the article concerns the implementation of assumptions related to the traffic incident management system in the aspect of road infrastructure in theoretical and empirical terms, the methodology oscillates around the creation of knowledge, enabling the achievement of a specific goal implied by intelligent logistics systems, including critical ones, the essence of traffic incident management, intelligent transport systems and through the use of event management algorithms.

\subsection{Telematic Systems in Transportation}

From the scientific perspective, the term "telematics", which combines telecommunication and computer science, brings together the achievements of three fields - telecommunication, computer science and automatics. Telematic solutions are used, for instance, in industry and medicine, but they also constitute a crucial element of modern transportation systems. The term telematics refers to a set of technological solutions that can improve transportation, forwarding and logistics processes, among other things, increasing their safety and performance and reducing their negative environmental impact. No matter in which area of the broad sector of transportation, forwarding and logistics telematics is used, an important aim of implementing telematics-based systems is time saving, which is directly translated into reduction of costs, including transportation costs (Schnieder, L., \& Lemmer, K., 2014).

Transportation telematics refers mainly to technological solutions that are part of so-called Intelligent Transportation Systems (ITS). ITS comprises three basic, intelligent groups of elements - vehicles, roads and management centres, which are equipped with modern devices and applications, such as: the Internet, radio communication systems, mobile networks, graphic databases, satellite navigation systems, cameras, radars, weather monitoring devices and many more (Noll, B., 2018).

\subsection{Intelligent Transportation Systems and Management of Road Incidents}

In terms of management of road incidents with regard to road infrastructure, the term intelligence is increasingly used to describe modern, pioneer, and sometimes even revolutionary, products, management techniques and technologies. In the theory of psychology, intelligence is often identified with various capacities: cognitive capacity, capacity for rational thinking and inferring, purposeful behaviour, coping in a complex environment and learning from experience. Although they are usually reserved to a human being, they can also be interpreted with regard to intelligent transportation systems (Ulusay-Alpay, B., 2016).

An intelligent transportation system is one that consists of interlinked elements such as: transportation linear infrastructure, nodal infrastructure, traffic participants and traffic managing entities, which deliver common transportation objectives and show capacity for processing generated information and capacity for adapting to changing conditions, which is manifested in ability to solve transportation problems with a different degree of difficulty and complexity based on previously processed information, applied expert programmes or algorithms that enable right decisions to be made with regard to transportation system management (Dyr, T., 2015). However, the pace of today's technological progress suggests that in the near future this range of possibilities will also include a system's ability to learn.

It is indicated that in ITS the ability to solve complex transportation problems is a result of the use of various tools that rely on IT technology, wireless communication and electronics of transportation means. The above-listed tools are advanced applications designed to provide innovative services connected with management of traffic and the processes of the flow of information between the transportation system's users in order to ensure a secure and rational use of the transportation network (Kleen, P., et al., 2018).

Simplifying the essence of ITS in terms of road incident management in the aspect of road infrastructure, it can be assumed that this system comprises management centres, which are connected by means of specific IT, automatic and communication solutions with transportation infrastructure used by vehicle drivers (Figure 1). 


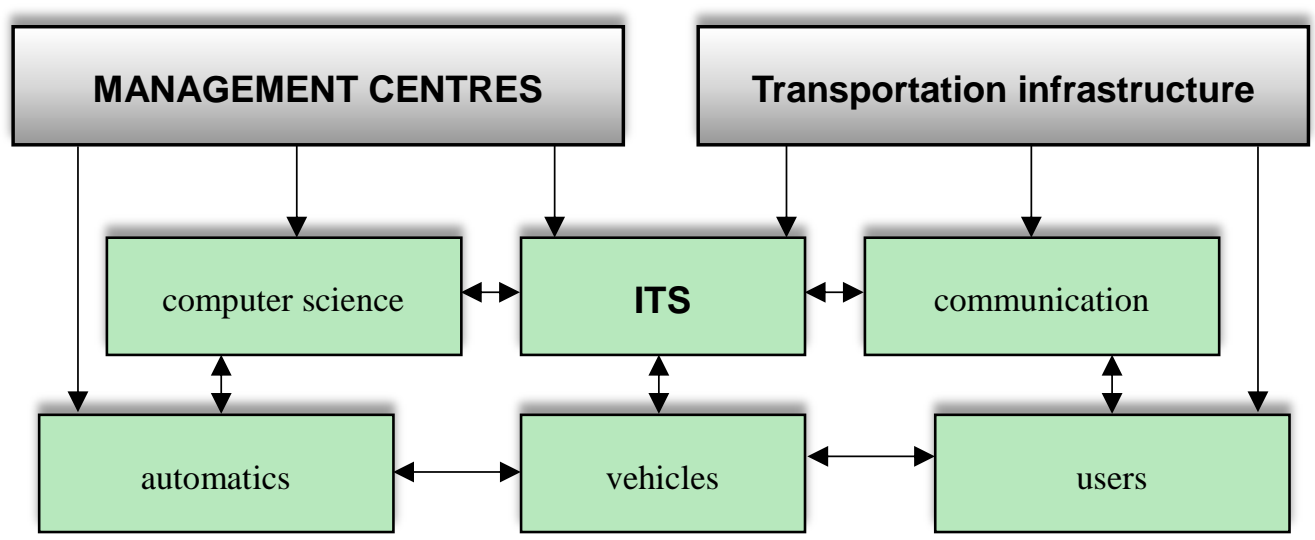

Figure 1. Components of ITS

Source: own work based on Kleen, P., et al. (2018). Funktionale Sicherheit von autonomen Transportsystemen in flexiblen I4. 0 Fertigungsumgebungen. In: Echtzeit und Sicherheit. Springer Vieweg, Berlin, Heidelberg, pp. 11-20.

Often, the term "telematics" is incorrectly used interchangeably with the term ITS. Telematics is a set of telecommunication, IT and automatic control solutions that are adapted to be used in physical systems. Intelligent systems are physical systems that have been improved by implementation of telematic solutions. In this sense, ITS is a broader concept than telematics.

Telematic solutions can be used as tools for supporting decision making processes in the area of road incident management in the aspect of road infrastructure, because they enable access to information in real-time, i.e. information that is updated on an ongoing basis, and thereby find a range of applications in the management of traffic, both urban and suburban. The complex of such solutions should be integrated in one coherent network covering the entire transportation system (Eck, F., 2015). A transportation system referred to as intelligent should use at least several of the available telematic solutions that have a real impact on the improvement of the effectiveness of the movement of goods and people as part of the system and on increased safety of transport.

\section{Urban Agglomeration}

Urban agglomerations are areas with the highest concentration of population and the greatest capability to create economic growth (Kołodziejski, H., \& Wyszomirski, O., 2017), struggling at the same time with numerous economic, social, spacial, infrastructural and ecological problems. Cities are also areas with a particularly high rate of mobility resulting in road incidents (Siergiejczyk, M., et al., 2015). Therefore, the key barriers to the development of modern cities include: congestion, low level of traffic safety and high level of pollution of the environment.

Congestion is crowding or overloading of city streets (Dyt, T., \& Kozłowska, M., 2018). Such phenomenon causes a range of negative effects. They include traffic jams on main arteries connecting the different areas of cities, which significantly deteriorate the conditions of transporting both humans and loads. A negative effect of congestion is also a significant reduction of traffic speed, which sometimes may even paralyse communication in certain city zones. As numerous studies conducted in Europe show, the speed of vehicles on roads in big cities are reduced to even 5-10 $\mathrm{km} / \mathrm{h}$, i.e. the walking pace of an average pedestrian. Another negative effect of congestion is time losses suffered by inhabitants, deliverers and carriers. Among the negative consequences are also increased costs of vehicle use and infrastructure maintenance, as well as road incidents. Congestion is thought to be caused by a surge in the number of vehicles on roads which is not compensated by the proportional increase in road infrastructure capacity (Schuwerk, G., \& Schueller, H., 2015).

Solutions are sought to eliminate or reduce congestion by examining such parameters as: population density in a city and its individual districts, the number of people employed in a city, the number and location of production and services companies in a city, the number and location of outlets, cultural, recreational and entertainment facilities, eating places, healthcare and educational institutions, and then analysing trips between the above-listed facilities. One of such solutions is to build and operate logistics centres. They enable a significant reduction of heavy goods traffic in cities by using light commercial vehicles, among other things (Hundert, M. (2018). This is because shipment consolidation and deconsolidation constitutes integral services of warehouse management in logistics and distribution centres. Such facilities, which also carry out tasks connected with collection, reloading, storage, picking, packaging and distribution of goods, are usually located on the outskirts of cities handling large load streams (Dalaff, 
C., Niebel, W., \& NeumanN, T., 2014). Additional benefits of their functioning include reduction of noise and air pollution in a city. These are important advantages, because vehicles produce huge quantities of highly harmful substances for human health during rapid and incomplete combustion, especially during rush hours.

However, urban authorities have a wide range of possibilities at their disposal to reduce cargo transport in urban areas. The most popular solutions include limits on traffic routes, time (e.g. deliveries beyond peak hours) and on vehicles' technical parameters (permissible load capacity or vehicle height on selected road sections or in selected urban zones).

\section{Implementation of Telematic Solutions in Urban Agglomerations}

The implementation of ITS, which is based on various telematic solutions, can bring a range of benefits to urban transportation systems and their users (Figure 2), and be an alternative in solving the above-mentioned urgent problems of cities, including those related to road incidents.

One of the advantages of the implementation of ITS solutions is an increase in the effectiveness of transportation entities, e.g. by shortening transport time or reducing energy consumption. Another significant positive effect is improvement of the natural environment through reduction of traffic in selected areas or routes, and, as a result, reduction of exhaust emission and noise level. Other highlighted advantages include increased traffic safety and better protection of traffic participants (Bubeck, A., et al., 2014).

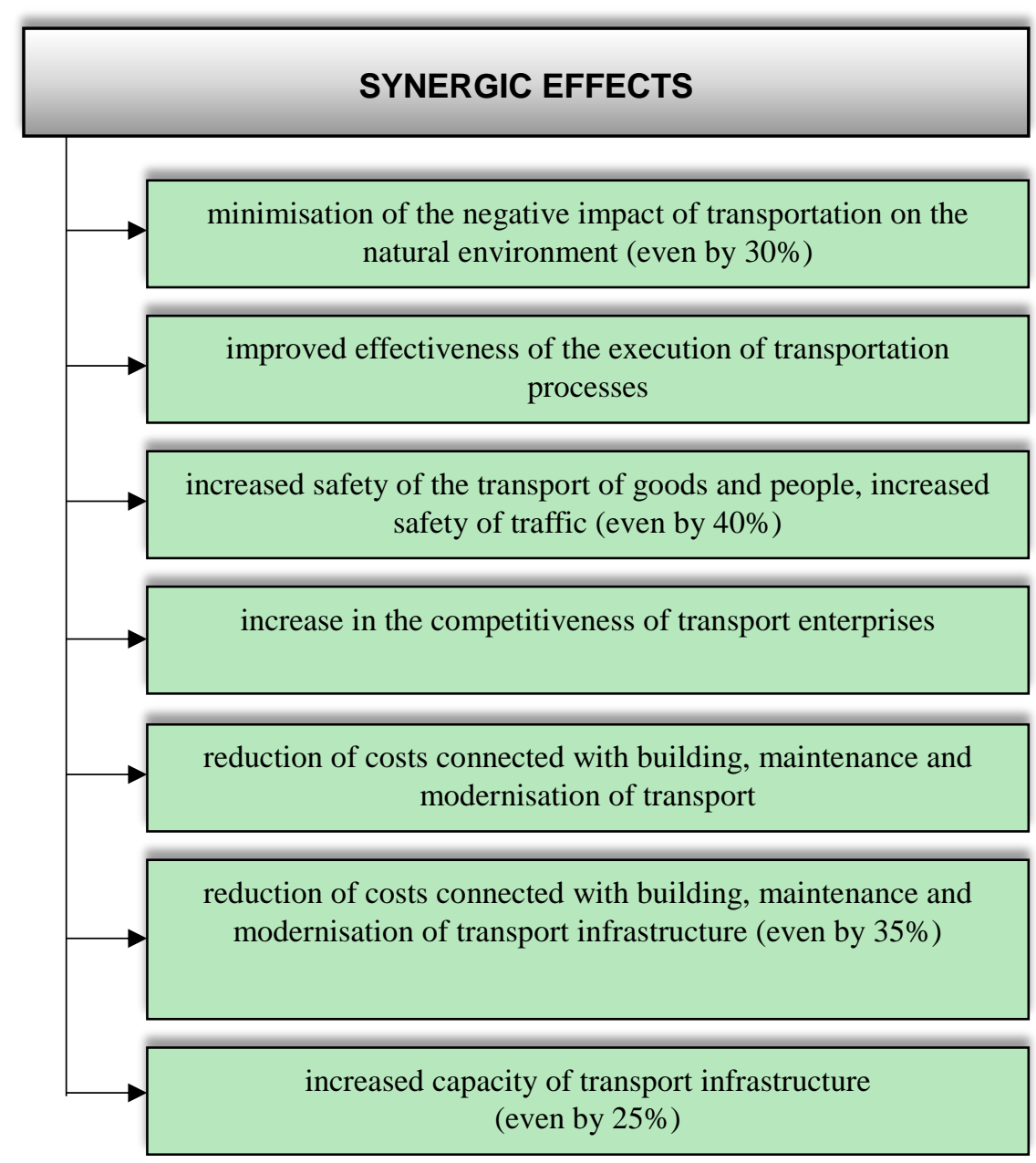

Figure 2. Selected benefits of the implementation of ITS solutions in transportation

Source: own work based on Bubeck, A., et al. (2014). Vom fahrerlosen Transportsystem zur intelligenten mobilen Automatisierungsplattform. In: Industrie 4.0 in Produktion, Automatisierung und Logistik. Springer Vieweg, Wiesbaden, pp. 221-233. 
Occurrence of several effects at the same time may contribute to effects of synergy. For example, improved effectiveness of transportation processes and reduced costs of road incident management may cause carriers to make new investments in urban communication.

For such effects to occur, it is necessary to create ITS architecture, i.e. the structure of system elements that constitutes a kind of framework that allows relations to be created and the different system elements to be integrated and to cooperate with each other and with the environment (Kirsch, Ch., et al., 2016). Such elements can be adjusted to each other thanks to standardisation of telematic systems.

Creation of ITS that functions as a subsystem of the urban logistics system should begin with identification of functional areas where specific telematic solutions could be implemented in order to achieve measurable benefits related to the traffic of people and goods, including reduction of congestion, level of pollution and noise, and increased traffic safety through appropriate management of road incidents and appropriate road infrastructure. Scholars and experts in the field of transportation as well as good practices in selected European cities show that such areas include: urban communication management system, system for managing urban traffic safety, system for road incident management, vehicle management system, electronic payment collection system, electronic ticket system, and electronic and dynamic system of passenger information (Malleck, H., \& Mecklenbräuker, Ch., 2015).

While designing ITS, it is also necessary to indicate specific technological, IT, communication, automatic and measurement solutions, i.e. application areas, with which each functional area will be equipped. It is worth emphasising that some of them may use multiple solutions, while in the case of others, it seems reasonable to implement only one solution. An important issue is analysis of current values of such parameters as mobility on streets or street capacity, as well as assessment of whether the implementation of a specific telematic solution is necessary and will bring expected economic, social and environmental benefits. This can be achieved by means of simulation techniques, which rely, among other things, on expert programmes and neural networks.

The following systems can be used in urban communication management subsystem: AVLS, GPS, GIS, databases and variable message boards located near communication nodes. The aim of variable message boards is to inform users of the urban transportation system about possible variants of travelling, e.g. by bus, underground or tram, about real-time public transport timetables, i.e. showing potential delays, about tariffs, ticket distribution systems and enforcement regulations, e.g. regulations concerning transport of luggage and animals.

An interesting tool in the subsystem of traffic safety management is variable message signs, which inform about maintenance work in selected road sections, closure of certain streets, and collisions or road incidents that impede traffic in selected sections of a city's linear infrastructure. In such cases, users are informed about such incidents as they happen, which allows them to take decisions optimising their trips within a city. Such signs lead to reduction of the speed of vehicles and reduction of the number of offences, thereby increasing road traffic safety.

The most interesting solutions in the subsystem of road incident management in urban areas include automatic incident detection, TV control systems, traffic monitoring devices - sensors, detectors, video detectors - which enable identification of traffic offenders.

As far as vehicle management systems are concerned, it is worth mentioning GPS, GIS, radio communication systems (RDS and RFID), automatic vehicle location systems (AVLS) and decision support systems. GPS-based applications are used on a wide scale (both by transport companies and individual users), mainly due to the benefits they offer. Implemented in an enterprise, they enable constant monitoring and control of vehicle fleet. They make it possible to precisely locate vehicles, plan itineraries in real time and monitor various driving parameters (Zimmermann, W., \& Schmidgall, R., 2014).

GPS-based applications are designed to process and visually present information connected with the location of various objects in space (e.g. warehouse facilities, production halls). Such applications include: databases, digital maps and software. They make it possible to analyse information about roads under repair, damaged road surfaces or bad conditions in a particular road section.

The implementation of an electronic payment collection system may reduce the load on a city's transportation infrastructure and decrease congestion in the area covered by the payment system. Charging road traffic participants with payments for entry to certain zones of the city is intended to reduce traffic within the city, contribute to protection of historic urban zones and reduce nuisances connected with congestions and noise.

Another solution, which is very popular with users of urban transport systems, is an electronic ticket system, which is designed to make it easier for urban public transport users to travel. Its implementation can be difficult in cases when it should fulfil the role of a document that entitles to travelling by multiple means of transport. A huge challenge for 
operators and transport companies is then to unify the tariff system. In the future, an electronic ticket should also be integrated with a parking fee system in the paid parking zones.

However, the implementation of ITS solutions can be difficult, due to economic and also organisational and mentality-related considerations. It is thus recommended to conduct educational campaigns to raise awareness among the users of transport systems and the entities managing such systems of such risks as low traffic safety resulting in road incidents, as well as promote specific ITS solutions.

The implementation of ITS aims to support the management of traffic, public transport and vehicle fleet, to simplify the operation of transport payment systems, to support road incident management, to improve safety and information control systems and to support the management and maintenance of road infrastructure (Ress, Ch., \& Wiecker, M., 2016). A detailed scope of ITS application in the form of services that are provided is presented in Table 1.

The scope of ITS application, as presented in Table 1, comprises services that can be provided thanks to the earlier-mentioned devices and applications with a varied scope of offered data and various ways of its processing, presentation and use. Telematic systems are a source of data, which can be grouped in terms of its origin into (Borowiak, J., Jaśkiewicz, K., \& Wąsowicz, A., 2018):

- directly derived from a telematic device,

- $\quad$ entered by a vehicle driver,

- derived from a motor vehicle, a trailer or a semitrailer,

- provided by means of additional sensors.

Regardless of the type of applied devices or how data is derived in the different Intelligent Transportation Systems, what is important for determining the usability of a system is knowledge of its complexity - potential scope of interaction with the user of the suprastructure or infrastructure. Full interaction systems that enable a two-way flow of data between the system and its user are the most comprehensive and to the largest extent accelerate the flow of information. No less useful are systems without direct interaction (e.g. devices under a vehicle's dashboard that transmit data directly to the central control unit without the driver's knowledge) or one-way interaction systems that provide "driver - central control unit" or "central control unit - driver" communication (Nürnberger, S., 2018).

Table 1. Scope of the application of ITS

\begin{tabular}{|c|c|}
\hline APPLICATION AREAS & PROVIDED SERVICES \\
\hline $\begin{array}{l}\text { Traffic and trip } \\
\text { management }\end{array}$ & $\begin{array}{ll} & \text { pre-trip information } \\
\square & \text { on-trip driver information } \\
\square & \text { information on conditions of public transport trip and possibility of booking } \\
\text { such trip } \\
\square & \text { information on conditions of traveller services } \\
\text { traffic control } \\
\square & \text { management of rescue operations after an incident } \\
\square & \text { management of demand for traveller service } \\
\square & \text { control and reduction of a vehicle's exhaust emission } \\
\text { traffic control at road and rail junctions } \\
\square & \text { supporting the enforcement of traffic regulations } \\
\square & \text { management of the maintenance of line and point infrastructure } \\
\square & \text { vehicle guidance and navigation }\end{array}$ \\
\hline $\begin{array}{l}\text { Public transport } \\
\text { management }\end{array}$ & $\begin{array}{ll} & \text { informing travellers about changes } \\
\square & \text { personalised public transit } \\
\square & \text { control of public transport trip safety } \\
\square & \text { "on demand" transport management }\end{array}$ \\
\hline Transport payments & road use electronic payment services \\
\hline $\begin{array}{l}\text { Commercial cargo } \\
\text { carriages and vehicle fleet } \\
\text { management }\end{array}$ & $\begin{array}{ll} & \text { electronic check of vehicles used for commercial purposes } \\
\square & \text { automatic inspection of road safety } \\
\square & \text { On-board safety monitoring } \\
\text { improvement of administrative processes connected with the use of vehicles } \\
\text { for commercial purposes }\end{array}$ \\
\hline
\end{tabular}




\begin{tabular}{lll}
\hline & $\square$ & control of hazardous material transportation \\
& $\square$ & management of vehicle fleet used for commercial purposes \\
\hline Incident management & $\square$ & incident notification and safety of people \\
& $\square$ & emergency vehicle management \\
& $\square$ & notification of hazardous load transportation \\
\hline & $\square$ & collision prevention \\
Advanced systems of vehicle & $\square$ & prevention of collisions at junctions \\
safety & $\square$ & video anti-collision systems \\
& $\square$ & anti-collision robustness installations \\
& $\square$ & automatic vehicle operations \\
& $\square$ & anti-squash protection \\
Safety systems & $\square$ & public transport safety (including pedestrian safety) \\
& $\square$ & safety of disabled road users \\
Information control & $\square$ & intelligent junctions \\
\hline Management of the & $\square$ & use of archived data \\
construction and & & \\
maintenance of road & $\square$ & construction, repair operations \\
infrastructure & $\square$ & maintenance operations (including in particular in winter) \\
\hline Source: & & \\
\hline
\end{tabular}

Source: own work based on Nürnberger, S. (2018). Datenverarbeitung im (vernetzten) Fahrzeug. Datenschutz und Datensicherheit-DuD, Vol. 42, Nr. 2, pp. 79-82.

Intelligent Transportation Systems are often referred to as the key to efficient traffic management and safety improvement in terms of road incidents with regard to road infrastructure. Modern technological solutions such as traffic lights management systems, road monitoring, variable message signs and weather information are only few examples of the improvements implemented in transportation systems across the world. Growing road infrastructure requires improvements in traffic management that can generate time saving and reduce transportation costs, but just as important are priorities connected with improvement of traffic safety, in particular road safety.

\section{Discussion of the Principles That Should Be Applied When Choosing and Implementing ITS Applications and Services and Recommendations}

ITS is a telematic system that is deeply anchored in the physical environment from which it derives information and to which it returns the information once it has been processed appropriately. It comprises both devices and software. In this context, an ITS service can be identified with ITS sub-system, and it is this subsystem (the process of choosing and implementing it) that the below-described principles should apply. The principles below are very general in nature; most of them apply to services of different kind, not necessarily ITS. Such services should be based on rational bases of their provision, which are also economically, technically and socially effective. The principles laid down in the law serve well the processes of developing specifications at various levels in the form of provisions of law, guidelines and recommendations. It is more difficult to directly implement them in the processes of selection and implementation of ITS applications and services. In such processes, they may serve as general recommendations, as they are difficult to concretise. In order to apply them all, it would be necessary to propose a set of recommended criteria for compliance assessment for specified principles and for a specific service. It should be clearly emphasised at this point that in individual cases it is reasonable to only take into account a relevant subset of principles to assess a given ITS solution. In each case, assessment of effectiveness and cost-effectiveness should be made. An important issue is to ensure interoperability. Some principles, such as proportionality, supporting maturity or promoting an equal access, are very pragmatic. Others are more or less connected with particular ITS services, mainly at the stage of defining selected requirements and design. The remaining ones are either very obvious or very general.

\section{Research}

Traffic incident management methods in terms of road infrastructure use algorithms that allow the analysis of changes in traffic parameters such as vehicle speed, traffic volume and detector occupancy. In order to compare the effectiveness of individual algorithms, three main parameters were taken into account - detection rate (DR), false alarm rate (FAR) and time to detect (TTD). The detection rate is defined as the ratio of the number of detected events to the total number of events. The value of the indicator depends on how the event is defined. In some analyses, only lane events are taken into account, in some cases stopping the vehicle at the side of the road is also taken into 
account (Strubbe, T.,Thenée, N., \& Wieschebrink, C., 2017). The recognition of events that result in vehicles being immobilised on the roadside without interrupting or disrupting the flow of traffic is much lower. The detection time of an event shall be defined as the time interval between the occurrence of the event and its detection, without taking into account the time needed for its verification. The false alarm indicator is defined as a percentage of the number of wrongly detected events in the total number of detected events (Rausch, M.,Lämmer, S., \& Treiber, M., 2013). In most of the algorithms one decision is made - whether or not an event occurs in a given time interval, converted into a detection station. The ways of defining this parameter are different, due to different ways of calculation. Usually, the greater the number of decisions made per time unit and the greater the number of detectors in the network, the higher the false alarm rate. Due to the above, an additional indicator is often defined, which takes into account the number of false alarms per detection station, in time units (Lämmer, S., Treiber, M., \& Rausch, M., 2013).

The values of the described indicators are dependent on each other. As the detection rate increases, the false alarm rate also increases. Similarly, with smaller false alarm rates, lower detection rates were also observed due to lower sensitivity of the algorithm. On the other hand, with an increase in detection rate, the average detection time also increases. It is also possible to notice the dependence that with a decrease in the detection time of an event, the false alarm rate increases. This leads to the conclusion that if the algorithm analyzes the data for a longer period of time (longer detection time), the results are more satisfactory (detection rates are higher and false alarm rates lower). Certainly, the detection time of an event must not be too long, therefore a balance should be sought between the performance parameters of the method used (i. e. with an acceptable number of false alarms, an acceptable detection time and a satisfactory detection rate) (Liedecke, Ch., 2016).

In recent years, four main groups of traffic incident management algorithms have been developed and classified: algorithms based on reference models, algorithms based on catastrophe theory, algorithms based on statistical calculations and algorithms based on artificial intelligence (Harrer, M., Gunitzberger, R., \& Baumgartner, N., 2018). Algorithms based on reference models and based on statistical calculations have also been developed. The Artificial Intelligence method is the latest of the four methods mentioned above. Video image processing algorithms are presented as a separate group, in which algorithms from the groups mentioned above are often used (Netter, F., 2017).

Algorithms based on the reference models are the most common algorithms. They use information about motion flow parameters obtained from inductive loops, i. e. traffic volume and occupancy of the detector, comparing data from detectors with theoretical patterns derived from historical data. Algorithms in this group require an initial determination of the thresholds to which traffic parameters would be compared. Setting thresholds is difficult and time-consuming. This stage is very important, hence it should not be underestimated as the accuracy of the thresholds is a key element for the subsequent functioning of the algorithms. Algorithms in this group include the Californian algorithm (also known as the TSC algorithm), its subsequent modifications (TSC 7 and TSC8 algorithms), the APID algorithm (a component of the COMPASS software used in the Toronto motorway network, which is also a modification of the Californian algorithm), the PATREG algorithm and the Minnesota algorithm (Zhang K., \& Taylor A.P., 2005).

Algorithms based on catastrophe theory take into account the occurrence of a sudden, discrete change in one variable, while other dependent variables show continuous changes over time. The variables to be considered are vehicle speed, detector occupancy and traffic volume. In the event of a significant sudden drop in speed, without an increase in occupancy and traffic, an alarm is triggered. Thanks to this, the use of algorithms from this group allows to distinguish the occurrence of an event from the occurrence of a road congestion. The event causes an increase in the queue of vehicles and a sudden, significant drop in speed. The difference between algorithms based on catastrophe theory and algorithms based on patterns is that the reference method is based on the determination of changes in individual variables at predetermined thresholds, while in the catastrophe theory, many variables over time are compared with earlier trends in data variability. An example of an algorithm from this group is the McMaster algorithm (LI, Linchao, et al., 2016).

In algorithms based on statistical calculations, the current traffic flow data is compared with data obtained from forecasts, using time series. All changes in motion parameters beyond the predicted range of parameter values are classified as events by the algorithms. The advantage of using these algorithms is that they take a large amount of data into account. Algorithms classified within this category are: HIOCC (High Occupancy Algorithm), ARIMA (Auto-Regressive Integrated Moving-Average) algorithm, SND (Standard Normal Deviates) algorithm, DES (double exponential smoothing) algorithm, DELOS (Detection Logic with Smoothing) algorithm, Bayesian algorithm and SSID (Single-Station Incident Detection) and the Low Pass Filter (Shapilsky, V., et al., 2017).

Artificial intelligence is used in the youngest group of traffic incident management algorithms. Neural networks and the theory of fuzzy sets are used here. The disadvantage of neural networks is a high proportion of false alarms and relatively long time needed to detect events. This is primarily due to preliminary assumptions, which impose on 
neural networks the task of recognising congestion conditions caused by exceeded throughput from congestions caused by events. The recognition process mentioned above significantly extends the detection time, however in comparison with other algorithms, it is satisfactory.

Conducting research to compare traffic incident management algorithms has proved to be a very difficult task due to the variety of traffic conditions at the research sites, meteorological conditions and the number and variety of detectors used to collect data. However, the results presented in Table 2 may serve as a basis for the evaluation of the solutions applied.

Differences in the effectiveness of algorithms are significant. For example, the use of Bayesian algorithm allows to detect all events and, at the same time, no false alarms, but with the highest value of time to detect events. Among the algorithms tested, APID and DES algorithms performed best. The APID algorithm reached a detection rate of $43 \%$, an average detection time of 1.25 minutes and a false alarm rate of $0.03 \%$. The DES algorithm is faster - on average it detects an event in $0.35 \mathrm{~min}$. and has a higher detection rate - about $46 \%$, but with a large number of false alarms. It is also important to remember about the influence of bad weather conditions on the implementation of algorithms. The APID algorithm showed high resistance to that type of errors. The McMaster algorithm, on the other hand, showed an increase in the false alarm rate during snowstorms. The Bayesian algorithm also proved to be sensitive to weather conditions. The SND and DES algorithms tolerated moderate changes in weather conditions.

Table 2. A summary of the results of the analysis of individual algorithms

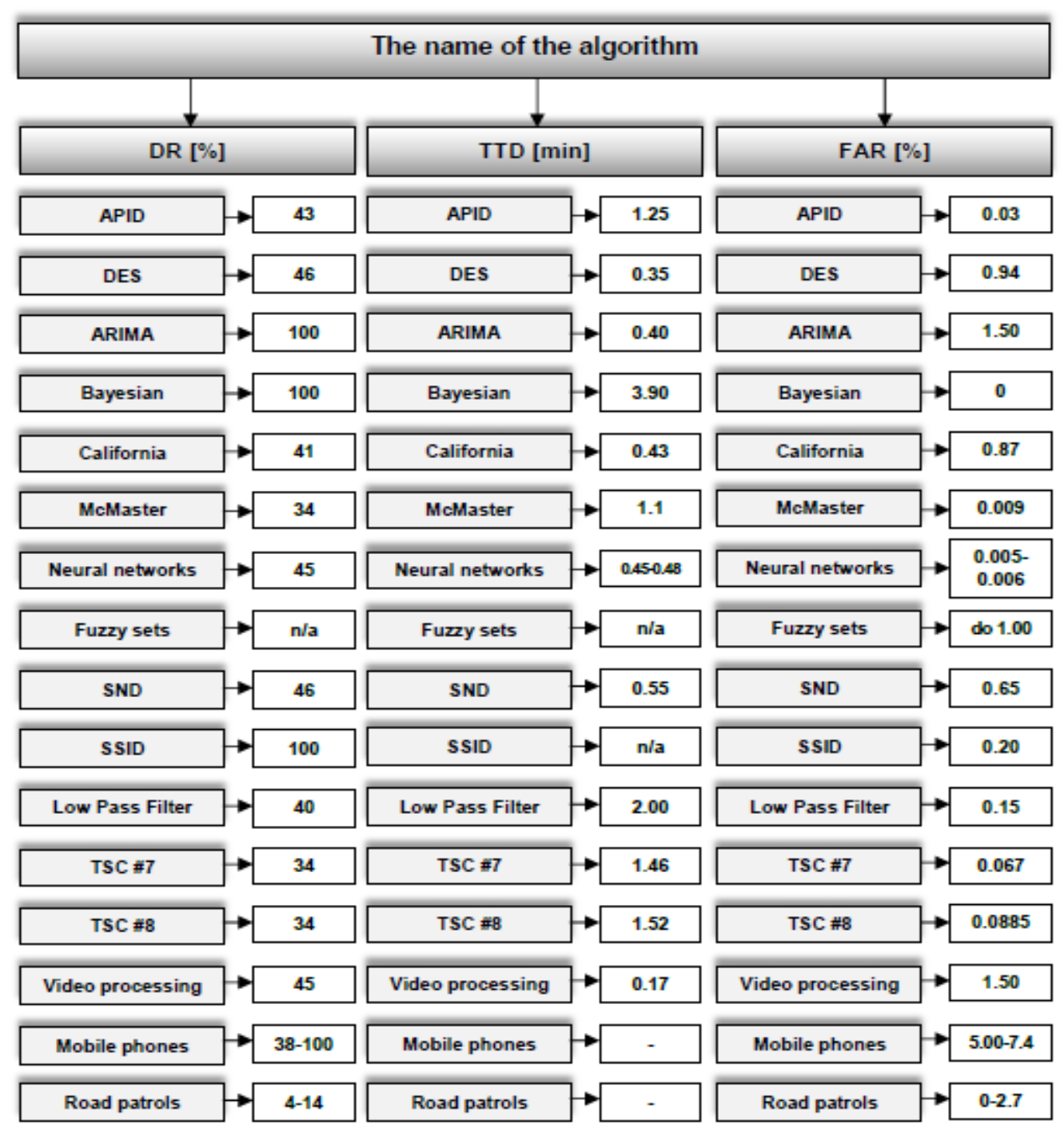

Source: own work. 
Results of the research carried out in view of different effects of the application of particular algorithms in different traffic conditions, traffic volume and meteorological conditions, allowed us to assume that it is justified to combine different algorithms in a single method of event detection, combining two or more methods in order to maximise the effectiveness of traffic incident management. The fusion of algorithms is not a complex task because they use the same detection tools that collect the same or similar data in comparable time frames. If several algorithms are used at the same time, the decision on the occurrence of an event may be determined by the occurrence of alarms for most of the algorithms used in the merger. The use of several event detection methods at the same time may have even greater impact on the effectiveness of the traffic incident management system.

\section{Conclusion}

The aim of the article has been achieved by indicating the variety of applications of intelligent transport systems, logistics and algorithms in the implementation of tasks at the level of traffic event management:

- Although appropriate algorithms have been shown to improve the current functioning of transport systems, thereby increasing their efficiency and reducing their negative impact on road infrastructure, they require significant data logging efforts as information may not be collected and processed properly. However, a wide range of applications of artificial intelligence systems allows them to be systematically implemented.

- It is worth noting that the results of the analysis of individual algorithms presented by the authors are so reliable and significant that if they could be integrated with the existing road infrastructure, they would contribute to the development of optimal strategies for managing traffic incidents.

- A thorough evaluation of the research outcomes allowed the authors to indicate the practical aspects of their application in the form of comprehensive ICT solutions, enabling the management of traffic incidents using ICT instruments and algorithms.

- Intelligent transport systems and logistic systems, as well as algorithms may be applied in situations of variable traffic parameters and the occurrence of factors causing this variability, so decision-makers could use the suggested algorithms and other indicated telematic solutions to solve the tasks related to traffic incident management in relation to various types of road infrastructure.

- The implementation of ICT modules and algorithms constitutes a solution and a helpful instrument in the event of a disrupted flow of traffic caused by an incident and can significantly contribute to improving traffic safety.

\section{References}

Borowiak, J., Jaśkiewicz, K., \& Wąsowicz, A. (2018). Computer science in the management of a transport company. AUTOBUSY-Technika, Eksploatacja, Systemy Transportowe, 19(6), 1021-1025.

Brzozowska, A., Bubel, D., \& Kalinichenko, A. (2019). Analysis of the Road Traffic Management System in the Neural Network Development Perspective. Vostocno-Evropejskij Zurnal Peredovych Technologij, 2(3), 98.

Bubeck, A., et al.. (2014). Vom fahrerlosen Transportsystem zur intelligenten mobilen Automatisierungsplattform. In Industrie 4.0 in Produktion, Automatisierung und Logistik (pp. 221-233). Springer Vieweg, Wiesbaden.

Dalaff, C., Niebel, W., \& NeumanN, T. (2014). Was ist eigentlich Qualitaet?-Versuch einer begrifflichen Konsolidierung und Systematik im Verkehrsmanagement/What is Q quality?-Terms and systematization in context of traffic management. Straßenverkehrstechnik, 58(9), 601-606.

Dreier, J. (2018). Verkehrsmanagementzentrale der Schweiz. In Verkehrsmanagementzentralen für Autobahnen (pp. 73-105). Springer Vieweg, Wiesbaden.

Dyr, T. (2015). Konkurencyjna i zasobooszczędna mobilność w miastach. Autobusy: technika, eksploatacja, systemy transportowe, (16), 50-56.

Dyt, T., \& Kozłowska, M., (2018). Congestion costs in the European Union. AUTOBUSY-Technika, Eksploatacja, Systemy Transportowe, 19(1-2), 26-31.

Eck, F. (2015). Digital, sicher, vernetzt, individuell. Intelligente Mobilitaet braucht einen Aktionsplan. Internationales Verkehrswesen, 67(1), 16-17.

Fröhlich, S., et al.. (2018). Nutzung von Verkehrsdaten zur Verkehrsflussoptimierung. In Management digitaler Plattformen (pp. 93-107). Springer Gabler, Wiesbaden. 
Harrer, M., Gunitzberger, R., \& Baumgartner, N. (2018). Das Verkehrsmanagementsystem und die Verkehrsinformationsdienste der ASFINAG. In Verkehrsmanagementzentralen für Autobahnen (pp. 11-71). Springer Vieweg, Wiesbaden.

Harrer, Manfred, et al.. (2018). Das Verkehrsmanagementsystem und die Verkehrsinformationsdienste der Asfinag. In Riegelhuth, G., \& Sandrock, M. (Eds.), Verkehrsmanagementzentralen für Autobahnen: Aktuelle Entwicklungen aus Deutschland, Österreich und der Schweiz (pp. 11-71). Springer-Verlag, Wiesbaden.

Hochgürtel, H. (2018). GPS-und Mobilfunkdaten in Verkehrsplanung und Verkehrsmanagement. In Mobilität und digitale Transformation (pp. 597-608). Springer Gabler, Wiesbaden.

Hundert, M. (2018). Metropolizacja jako symulanta czynników wywołujących kongestię. Gospodarka Materiałowa $i$ Logistyka, (7), 30-38.

Kirsch, Ch., et al.. (2016). Schlüsseltechnologien für intelligente, mobile Transport-und Automatisierungsplattformen. Handbuch Industrie 4.0: Produktion, Automatisierung und Logistik, 1-17.

Kleen, P., et al.. (2018). Funktionale Sicherheit von autonomen Transportsystemen in flexiblen I4. 0 Fertigungsumgebungen. In Echtzeit und Sicherheit (pp. 11-20). Springer Vieweg, Berlin, Heidelberg.

Kleine-Besten, T., et al.. (2015). Navigation und Verkehrstelematik. In Handbuch Fahrerassistenzsysteme (pp. 1047-1079). Springer Vieweg, Wiesbaden.

Kołodziejski, H., \& Wyszomirski, O. (2017). Tariffs and ticketing integration of collective public transport in the region at the example of Pomorskie Voivodeship. Transport Economics and Logistics, (70), 85-94.

Lämmer, S., Treiber, M., \& Rausch, M. (2013). Inflow-Regulating Traffic Light Control to Avoid Queue-Spillovers in Urban Road Networks. In Proceedings of the 3rd International Conference on Models and Technologies for Intelligent Transportation Systems, pp. 23-34.

Li, Linchao, et al.. (2016). Bagging-SVMs algorithm-based traffic incident detection. In CICTP 2016, pp. 1461-1469.

Liedecke, Ch. (2016). Anwendung haptischer Signale. In Haptische Signale am Fahrerfuß für Aufgaben der Fahrzeugsteuerung (pp. 87-94). Springer Vieweg, Wiesbaden.

Malleck, H., \& Mecklenbräuker, Ch. (2015). Die Digitalisierung des Verkehrs-Mobilität 4.0. e \& i Elektrotechnik und Informationstechnik, 132(7), 371-373.

Netter, F. (2017). Künstliche Intelligenz im Auto-Applikationen, Technologien und Herausforderungen. ATZelektronik, 1(12), 20-25.

Noll, B. (2018). Stadtverkehr der Zukunft - Stressfrei durch den Strassenverkehr. Strassenverkehrstechnik, 62(3), $172-176$.

Nürnberger, S. (2018). Datenverarbeitung im (vernetzten) Fahrzeug. Datenschutz und Datensicherheit-DuD, 42(2), 79-82.

Pieper, S., Kunde, F,. \& Sauer, P. (2018). Data Mining auf Verkehrsdaten. In Management digitaler Plattformen (pp. 125-145). Springer Gabler, Wiesbaden.

Rausch, M., Lämmer, S., \& Treiber, M. (2013). Reducing the impact of traffic incidents using capacity-regulating traffic lights. In Proceedings of the $3^{\text {rd }}$ International Conference on Models and Technologies for Intelligent Transportation Systems, pp. 89-98.

Ress, Ch., \& Wiecker, M. (2016). Potenzial der V2X-Kommunikation für Verkehrssicherheit und Effizienz. ATZ-Automobiltechnische Zeitschrift, 118(1), 16-21.

Reusswig, A. (2018). Digital, kooperativ, automatisiert: Die Verkehrszentrale Hessen als Impulsgeber für den intelligenten Verkehr im 21. Jahrhundert. In Verkehrsmanagementzentralen für Autobahnen (pp. 109-169). Springer Vieweg, Wiesbaden.

Schäfer, M., \& Hoyer, R. (2017). Bewegte Beobachter zur mobilen Erfassung netzweiter Verkehrszustände. In Innovative Produkte und Dienstleistungen in der Mobilität (pp. 267-283). Springer Gabler, Wiesbaden.

Schieweck, S., Kern-Isberner, G., \& Ten Hompel, M. (2018). Antwortmengenprogrammierung für autonome Fahrzeuge im innerbetrieblichen Verkehr. In Mobilität und digitale Transformation (pp. 567-581). Springer Gabler, Wiesbaden. 
Schnieder, L., \& Lemmer, K. (2014). Anwendungsplattform Intelligente Mobilitaet. Die Entwicklung intelligenter Mobilitaetsdienste im realen Verkehrsumfeld. Internationales Verkehrswesen, 66(2), 62-63.

Schonlau, B., Krumbiegel, K., \& Seidel, D. (2018). Concept in-the-Loop-Methode für die Automatisierung von Transportsystemen. ATZ-Automobiltechnische Zeitschrift, 120(11), 40-45.

Schuwerk, G., \& Schueller, H. (2015). Unfallbasiertes Sicherheitsmanagement fuer die bestehende Strasseninfrastruktur. Hintergruende und Umsetzung in der Schweiz. Zeitschrift fuer Verkehrssicherheit, 61(3), $162-168$.

Shapilsky, V., et al.. (2017). D Incident detection systems in motorway tunnels. In 16th Australasian Tunnelling Conference 2017: Challenging Underground Space: Bigger, Better, More (p. 441). Engineers Australia.

Siergiejczyk, M., et al.. (2015). Reliability-Exploitation Analysis of Highway Transport Telematics Systems/Analiza Niezawodnościowo-Eksploatacyjna Autostradowych Systemów Telematyki Transportu. Journal of KONBiN, 33(1), 177-186.

Strubbe, T., Thenée, N., \& Wieschebrink, C. (2017). IT-Sicherheit in Kooperativen Intelligenten Verkehrssystemen. Datenschutz und Datensicherheit-DuD, 4(41), 223-226.

Ulusay-Alpay, B. (2016). Informationstechnologie unter Erreichbarkeit-intelligentes Transportsystem: eine Studie für den Stadtverkehr in Istanbul. In: REAL CORP 2016-SMART ME UP! How to become and how to stay a Smart City, and does this improve quality of life? Proceedings of 21 st International Conference on Urban Planning, Regional Development and Information Society. CORP-Competence Center of Urban and Regional Planning, pp. 369-374.

Zhang, K., \& Taylor, A. P. (2005). Towards transferable Incident Detection Algorithms, University of South Australia. Journal of Eastern Asia Society for Transportation Studies, 6, 2263-2274.

Zimmermann, W., \& Schmidgall, R. (2014). Kommunikation zwischen Fahrzeugen. In Bussysteme in der Fahrzeugtechnik (pp. 483-489). Springer Vieweg, Wiesbaden. 